\title{
INFLUENCIA DA TEMPERATURA SOBRE O POTENCIAL FISIOLÓGICO DE SEMENTES SORGO SACARINO APÓS OSMOCONDICIONAMENTO
}

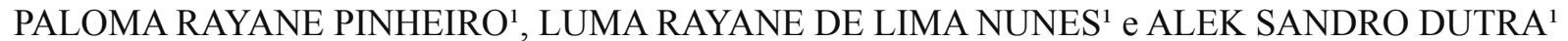

IUniversidade Federal do Ceará-UFC,palloma.ana@hotmail.com,lumanunes20@hotmail.come alekdutra@ufc.br.

Revista Brasileira de Milho e Sorgo, v.18, n.2, p. 299-310, 2019

\begin{abstract}
RESUMO - No solo as sementes se deparam com diversos fatores limitantes como o estresse hídrico e as altas temperaturas. Objetivou-se no presente trabalho avaliar o potencial fisiológico de sementes de sorgo sacarino após o condicionamento das sementes com PEG 6000 e expostas a diferentes temperaturas de germinação. O experimento foi conduzido em delineamento inteiramente casualizado distribuídos em parcelas subdivididas com três temperaturas $\left(20,25\right.$ e $\left.30^{\circ} \mathrm{C}\right) \times$ quatro lotes (L1, L2, L3 e L4) x cinco potenciais osmóticos $(0 ;-0,1 ;-0,2 ;-0,3$ e $-0,4 \mathrm{MPa})$. A temperatura consistia na parcela, os lotes como as subparcelas e os potenciais osmóticos como sub-subparcelas. Cada tratamento foi formado por 4 repetições. Após o condicionamento, as sementes foram submetidas às seguintes avaliações: porcentagem de germinação $(\mathrm{G})$, primeira contagem de germinação (PC), comprimento de parte aérea (PA) e radicular (PR), relação parte aérea/ raiz (PA/PR) e massa seca de plântulas (MS). O condicionamento osmótico influenciou de forma positiva a G e a PC para as sementes de sorgo sacarino nas temperaturas testadas, permitindo uma separação dos lotes quanto ao seu desempenho fisiológico. O condicionamento osmótico e o aumento da temperatura de germinação afetaram negativamente o crescimento das plântulas.
\end{abstract}

Palavras-chave: Sorghum bicolor (L.), condicionamento fisiológico, déficit hídrico, estresses abióticos.

\section{INFLUENCE OF TEMPERATURE ON THE PHYSIOLOGICAL POTENTIAL OF SORGHUM SORROW SEEDS AFTER OSMOCONDITIONING}

\begin{abstract}
In the soil the seeds are faced with several limiting factors such as water stress and high temperatures. The objective of this work was to evaluate the physiological potential of sorghum seeds after conditioning the seeds with PEG 6000 and exposed to different germination temperatures. The experiment was conducted in a completely randomized design distributed in subdivided plots with three temperatures $\left(20,25\right.$ and $\left.30{ }^{\circ} \mathrm{C}\right) \mathrm{x}$ four lots (L1, L2, L3 and L4) $x$ five osmotic potentials $(0,-0.1,-0,2,-0.3$ and $-0.4 \mathrm{MPa})$. The temperature consisted of the plot, the plots as the subplots and the osmotic potentials as sub-subplots. Each treatment consisted of 4 replicates. After conditioning, seeds were submitted to the following evaluations: germination percentage $(\mathrm{G})$, first germination count (PC), aerial part length (PA) and root (PR), shoot / root ratio (PA / PR) and dry mass of seedlings (DM). The osmotic conditioning positively influenced $\mathrm{G}$ and $\mathrm{PC}$ for the seeds of sorghum at the temperatures tested, allowing a separation of the lots in terms of their physiological performance. Osmotic conditioning and germination temperature increase negatively affected seedling growth.
\end{abstract}

Keywords: Sorghum bicolor (L.), physiological conditioning, water deficit, abiotic stresses. 
O sorgo (Sorghum bicolor (L.) Moench) é uma gramínea originária da África e parte da Ásia, que é cultivada em diversas partes do mundo, por se apresentar como uma importante fonte de alimento humano e animal, e se adaptar principalmente em regiões de déficit hídrico e alta temperatura (Simoni et al., 2011). É uma espécie do grupo $C_{4}$, assim, apresenta um metabolismo mais eficiente, pois minimiza a perda de água através da regulação da abertura e fechamento dos estômatos, o que possibilita a esta cultura uma maior tolerância a elevados níveis de radiação solar e uma alta taxa fotossintética (Albuquerque et al., 2012; Cunha \& Severo Filho, 2010; Pereira Filho et al., 2013).

A formação de estande e de grande impostaria para a cultura do sorgo, sendo que para a formação de um estande uniforme e vigoroso, faz-se necessário a utilização de sementes de qualidade e que apresentem uma germinação adequada, o que irá interferir diretamente na produtividade final da cultura (Simoni et al., 2011). Um dos motivos da perda de qualidade das sementes é a remoção da água das células até níveis não tolerados, o que pode ocorrer quando expostas a estresses, como o salino e o hídrico os quais levam a uma redução do gradiente de potencial entre a semente e o solo, impedindo que a semente absorva água (Pereira et al., 2014). Em condições naturais o estresse hídrico pode atuar de forma positiva para as plantas isso por levar a uma distribuição da germinação no espaço e no tempo aumentando as chances das plântulas encontrarem condições ideais para seu desenvolvimento (Bewley \& Black, 1994).

Além da disponibilidade de água, a temperatura também exerce um importante papel no processo germinativo, influenciando na velocidade, uniformidade e porcentagem de germinação, sendo que quando associado ao stress hídrico interfere na dinâmica de absorção de água, na velocidade das reações bioquímicas, e em eventos fisiológicos que determinam todo o processo germinativo (Silva et al., 2016). A temperatura ótima em que a maioria das espécies cultivadas apresentam maior taxa de germinação se encontra entre 15 e $30{ }^{\circ} \mathrm{C}$ (Medeiros et al., 2015), sendo que abaixo ou acima desses valores podemos observar estresse causados pela temperatura.

O condicionamento osmótico tem sido amplamente difundido para o controle da hidratação das sementes (Oliveira et al., 2011), o que possibilita uma ativação dos mecanismos fisiológicos das sementes, mas sem que ocorra a germinação. O polietilenoglicol (PEG) e o agente osmótico mais utilizado, por se tratar de um produto quimicamente inerte, não ser degradado, não penetrando nas células, e não causa toxidez nas sementes devido ao seu peso molecular. $\mathrm{O}$ osmocondicionamento apresenta-se como uma alternativa, pois favores o desempenho sob condições de setes hídrico pincipalmente em lotes de baixa qualidade, já que durante o período de embebição as sementes mais lentas (menos vigorosas) tendem a alcançar a sementes com germinação mais rápida, o que leva a uma maior uniformização na germinação, sendo que as condições de osmocondicionamento variam para cada espécie, variedade, e para a forma de aplicação do condicionamento (Simoni et al., 2011). No entanto o osmocondicionamento pode causar atraso no processo germinativo ou diminuir a germinabilidade final das sementes (Pelegrini et al., 2013; Rego et al., 2011), o que torna importante os estudos sobre a aplicação dessa técnica.

Com isso, o presente trabalho teve como objetivo avaliar o potencial fisiológico de sementes de sorgo sacarino após o condicionamento das sementes com PEG 6000 e expostas a diferentes temperaturas de germinação. 


\section{Material e Métodos}

O experimento foi realizado no Laboratório da Análise de Sementes do Departamento de Fitotecnia do Centro de Ciências Agrárias da Universidade Federal do Ceará, campus do Pici - Fortaleza, utilizando quatro de lotes de sementes de sorgo sacarino de diferentes épocas da cultivar BRS 506 sem beneficiamento, produzidas na Fazenda Experimental Vale do Curu/UFC na cidade de Pentecoste-CE. O experimento foi conduzido em delineamento inteiramente casualizado, distribuídos em parcelas subdivididas com três (temperaturas) x quatro (lotes) x cinco (potenciais osmóticos), com a temperatura constituindo a parcela, os lotes como as subparcelas e os potenciais osmóticos como sub-subparcelas. Cada tratamento foi formado por 4 repetições.

Antes de proceder com o condicionamento das sementes, realizou-se a determinação do teor de água das mesmas (TA), segundo o método da estufa a $105 \pm 3{ }^{\circ} \mathrm{C}$ por $24 \mathrm{~h}$ (Brasil, 2009), com uso de quatro subamostras de aproximadamente cinco gramas de sementes para cada lote. E a curva de embebição para definir o melhor intervalo de tempo para o condicionamento. Para isso, as sementes foram pesadas e colocadas em rolos de papel do tipo Germitest ${ }^{\circledR}$ umedecidos com água destilada na proporção de 2,5 vezes a massa do substrato e acondicionados em BOD (Biochemical Oxygen Demand) na temperatura de $25^{\circ} \mathrm{C}$. As sementes foram pesadas em balança digital com precisão de $0,001 \mathrm{~g}$ a cada intervalo de tempo prédeterminado (duas horas) até o momento em que foi observada a protrusão da raiz primária de pelo menos uma semente de cada repetição dos tratamentos, aproximadamente 18 horas. Para o condicionamento foi considerada a pesagem anterior àquela em que houve a protrusão da raiz primária das sementes (16 horas).
O condicionamento das sementes foi realizado em rolos de papel tipo Germitest ${ }^{\circledR}$, umedecidos com 2,5 vezes o peso do substrato por um período de 18 horas a $25^{\circ} \mathrm{C}$, com solução de PEG 6000 nas concentrações de $-0,1 ;-0,2 ;-0,3$ e -0,4 $\mathrm{MPa}$, conforme sugerido por Villela et al. (1991). Para o tratamento controle foram usadas sementes não condicionadas.

Em seguida, as sementes foram distribuídas em rolos de papel, umedecidos com água destilada na proporção de 2,5 vezes o peso do substrato. Para cada tratamento foram utilizadas 200 sementes, as quais foram distribuídas em 4 rolos de papel, com 50 sementes cada, e acondicionados em BOD às temperaturas constantes de 25,30 e $35^{\circ} \mathrm{C}$.

A primeira contagem e a contagem final do teste de germinação foram realizadas no quarto e décimo dia após a instalação do teste, respectivamente. Foi considerada a porcentagem de plântulas normais utilizando como critério de classificação, as definições estabelecidas nas Regras para Análise de Sementes (Brasil, 2009).

A análise do crescimento da parte aérea e da raiz foi realizado como descrito para a germinação sendo as análises realizadas aos dez dias após a instalação do teste, selecionando-se dez plântulas por tratamento, para proceder com as mensurações que foram auxiliadas por uma régua graduada em centímetros. Em seguida, essas plântulas foram levadas a estufa com circulação de ar forçada à temperatura constante de $65{ }^{\circ} \mathrm{C}$ por 72 horas. Logo após, foram pesadas em balança de precisão com três casas decimais para obtenção da massa seca, com os resultados expressos em miligramas, plântulas ${ }^{-1}$. Com base nos resultados obtidos para o crescimento da parte aérea e o radicular, foi calculada a relação PA/R, a partir da divisão dos valores. 
Os dados foram submetidos à análise de variância, ao nível de 5\% significância, no software estatístico SISVAR $®$ (Ferreira, 2011). Os resultados foram expressos através de regressão polinomial, sendo selecionado o significativo de maior $\mathrm{R}^{2}$. Para a representação gráfica dos resultados foi utilizada software Sigmaplot, versão 12.5 .

\section{Resultados e Discussão}

Houve interação significativa entre o condicionamento, às temperaturas e os lotes de sementes de sorgo para o comprimento da parte aérea e da raiz, massa seca da plântula e relação parte aérea/raiz. Para a germinação e primeira contagem houve efeito da interação entre o potencial osmótico e as temperaturas estudadas, a primeira contagem também apresentou interação significativa entre o condicionamento e os lotes (Tabela 1).

Analisando a porcentagem de germinação das sementes de sorgo sacarino baixo é possível observar que os valores de germinação (Figura 1) se mantiveram próximo a $100 \%$ mesmo com o aumento das concentrações de PEG 6000, sendo que na maior concentração, -0,4 Mpa tem-se uma leve diminuição na germinação para as temperatura de 25 e $30^{\circ} \mathrm{C}$ em

Tabela 1- Análise de variância para potencial osmótico de sementes de sorgo sacarino submetidas a diferentes temperaturas sobre o percentual de germinação $(\mathrm{G})$, primeira contagem de germinação (PC), comprimento da parte aérea (CPA) e da raiz (CR), Massa seca da plântula (MS) e relação parte aérea/raiz (PA/R).

\begin{tabular}{|c|c|c|c|c|c|c|}
\hline \multirow{2}{*}{ FV } & \multicolumn{6}{|c|}{ QM } \\
\hline & G & $\mathrm{PC}$ & MS & PA & PR & $\mathrm{PA} / \mathrm{R}$ \\
\hline Temp & $31,27^{\mathrm{ns}}$ & $140,47^{* *}$ & $0,0022 * *$ & $59,48^{* *}$ & $132,13 * *$ & $1,97 * *$ \\
\hline Erro 1 & 27,27 & 10,64 & 0,0001 & 0,34 & 0,69 & 0,01 \\
\hline Lotes & $108,72 * *$ & $428,49 * *$ & 0,00008 & $19,06 * *$ & $7,09 * *$ & 0,02 \\
\hline Lot $\mathrm{x}$ temp & $17,11^{\mathrm{ns}}$ & $18,42^{\mathrm{ns}}$ & $0,0004 * *$ & 1,82 & $4,06^{*}$ & 0,01 \\
\hline Erro 2 & 14,98 & 20,40 & 0,0001 & 1,22 & 1,30 & 0,01 \\
\hline Pot & $41,58 * *$ & $56,85 * *$ & $0,0012 * *$ & $400,91 * *$ & $162,60 * *$ & $4,59 * *$ \\
\hline Pot $\mathrm{x}$ temp & $38,18 * *$ & $38,11 * *$ & $0,0012 * *$ & $12,86^{* *}$ & $52,68 * *$ & $0,60 * *$ \\
\hline Pot $\mathrm{x}$ lot & $20,34^{\mathrm{ns}}$ & $38,23 * *$ & $0,0003^{* *}$ & $4,56 * *$ & $2,76^{* *}$ & $0,02 * *$ \\
\hline Pot $x$ lot $x$ temp & $11,97^{\mathrm{ns}}$ & $14,48^{\mathrm{ns}}$ & $0,0003 * *$ & $4,50 * *$ & $1,83^{*}$ & $0,03 * *$ \\
\hline Erro 3 & 11,59 & 13,91 & 0,000069 & 0,80 & 0,97 & 0,01 \\
\hline CV $1(\%)$ & 5,46 & 3,43 & 11,85 & 3,64 & 5,36 & 10,65 \\
\hline CV $2(\%)$ & 4,04 & 4,75 & 10,14 & 6,93 & 7,33 & 8,86 \\
\hline CV $3(\%)$ & 3,56 & 3,92 & 9,67 & 5,62 & 6,33 & 8,20 \\
\hline
\end{tabular}

* significativo ao nível de 5\%; ** - 1\%. ns - não significativo. Lot - lotes; Temp - temperaturas; Pot - Potencial osmótico. 
relação a temperatura de $35^{\circ} \mathrm{C}$, no entanto ainda se mantiveram próximo a $100 \%$ de germinação.

Diversos estudos comprovam que a germinação de outras espécies é reduzida à medida que decrescem os níveis de potencial osmótico do substrato. Em sementes de sorgo, Simoni et al. (2011), não observaram diferença até o potencial de $-0,4 \mathrm{MPa}$, mas a partir de -0,6 $\mathrm{MPa}$, houve uma queda no poder germinativo e quando expostas a -1,5 $\mathrm{MPa}$, não ocorreu a protrusão da raiz primária. Christovam et al. (2015), avaliando a germinação de sementes de Urochloa brizantha em condições de estresse hídrico, observaram uma redução à medida que se aumentou o potencial osmótico, sendo mais agravada no nível de -0,9 e -1,2 $\mathrm{MPa}$. Em milho, foi observado que a germinação foi afetada quando submetidas aos potenciais osmóticos, induzidos por manitol, de -0,9 e -1,2 MPa (Kappes et al., 2010).

No entanto, outros autores também atribuem a redução do poder germinativo das sementes à eleva- ção térmica. Zucareli et al. (2011), em milho comentaram que a menor porcentagem de germinação ocorreu sob a temperatura de $20{ }^{\circ} \mathrm{C}$. Sbrussi e Zucareli (2014), trabalhando com a mesma espécie, relataram que quando expostas a $16^{\circ} \mathrm{C}$, foi observada ausência de plântulas normais; e as temperaturas de 37 e $40{ }^{\circ} \mathrm{C}$, mostraram-se drásticas para as sementes, acarretando decréscimos nessa variável.

Em relação à primeira contagem de germinação, na figura 2 A verifica-se que o lotes 1 apresentou um aumento no número de plântulas normais conforme se reduziu o potencial osmótico do condicionamento. Já os lotes 2 e 3 mantiveram sua germinação com o aumento doas concentrações de PEG, ficando próximo a $100 \%$. Não houve diferença significativa para os potenciais osmóticos testados para o lote 4 (Figura 2A).

Oliveira e Gomes-Filho (2011), observaram que o condicionamento osmótico proporcionou um aumento no percentual de plântulas normais no teste de primeira contagem para os lotes de sementes de

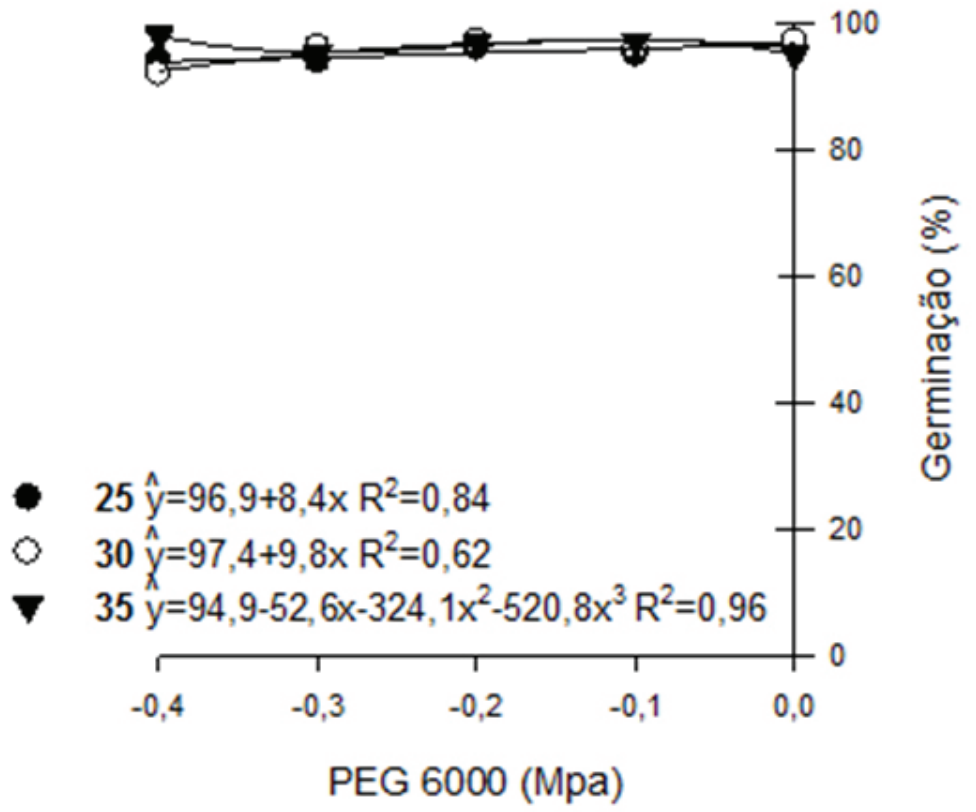

Figura 1 - Germinação de sorgo sacarino com sementes osmocondicionadas e submetidas a diferentes temperaturas. 
maior vigor, o mesmo não sendo observado em lotes de baixo vigor. No entanto, Lima e Marcos Filho (2010), comentaram que os efeitos do condicionamento fisiológico foram mais evidentes nos lotes de sementes de pepino com menor vigor. Assim sendo os lotes 2 e 3 por possuírem alto vigor não forma afetados pelo condicionamento, já o lote 1 que se mostrava valores menores de $\mathrm{PC}$ quando não submetidos ao PEG pode expressar melhor as vantagens do osmocondicionamento.

Ainda para a variável primeira contagem de germinação foi observada um aumento nesta, resultante da interação entre temperatura e níveis de PEG 6000 avaliados, com o número de plântulas normais aumentando, conforme se reduzia o potencial osmótico do condicionamento independente da temperatura empregada para germinação (Figura 2B). Resultados semelhantes foram encontrados por Lima e Marcos Filho (2010), em sementes de pepino, afirmando que, o osmocondicionamento em solução de PEG -0,1 e -0,2 MPa promoveu resultados de porcentagem e velocidade de germinação mais elevados em relação a testemunha (sementes não condicionadas) a $15^{\circ} \mathrm{C}$. Mas, ao elevar essa temperatura a $20{ }^{\circ} \mathrm{C}$, percebeu-se uma germinação mais rápida.

Houve uma queda no crescimento da parte aérea nos lotes de sementes de sorgo testados, conforme se aumentou as concentrações de PEG 6000 para as temperaturas testadas (Figura 3). Essa diminuição do comprimento é causada pela redução da expansão celular devido a desidratação em decorrência do estresse hídrico (Taiz et al., 2017). Assim, para essa variável o condicionamento osmótico acabou causando um estresse para as plântulas.

Para o sistema radicular houve o efeito inverso ao observado para o crescimento aéreo para as temperaturas de 25 e $30{ }^{\circ} \mathrm{C}$, havendo um aumento no comprimento da raiz. Quando expostos a $35^{\circ} \mathrm{C}$, o crescimento não foi tão expressivo em relação as demais temperaturas testadas. Temperaturas mais elevadas $\left(30\right.$ e $\left.35^{\circ} \mathrm{C}\right)$ possibilitaram o maior crescimento, apresentando valores médios acima de 25,00 $\mathrm{cm}$; enquanto a $25{ }^{\circ} \mathrm{C}$ foram encontrados os menores valores, em que, até mesmo na testemunha, esses
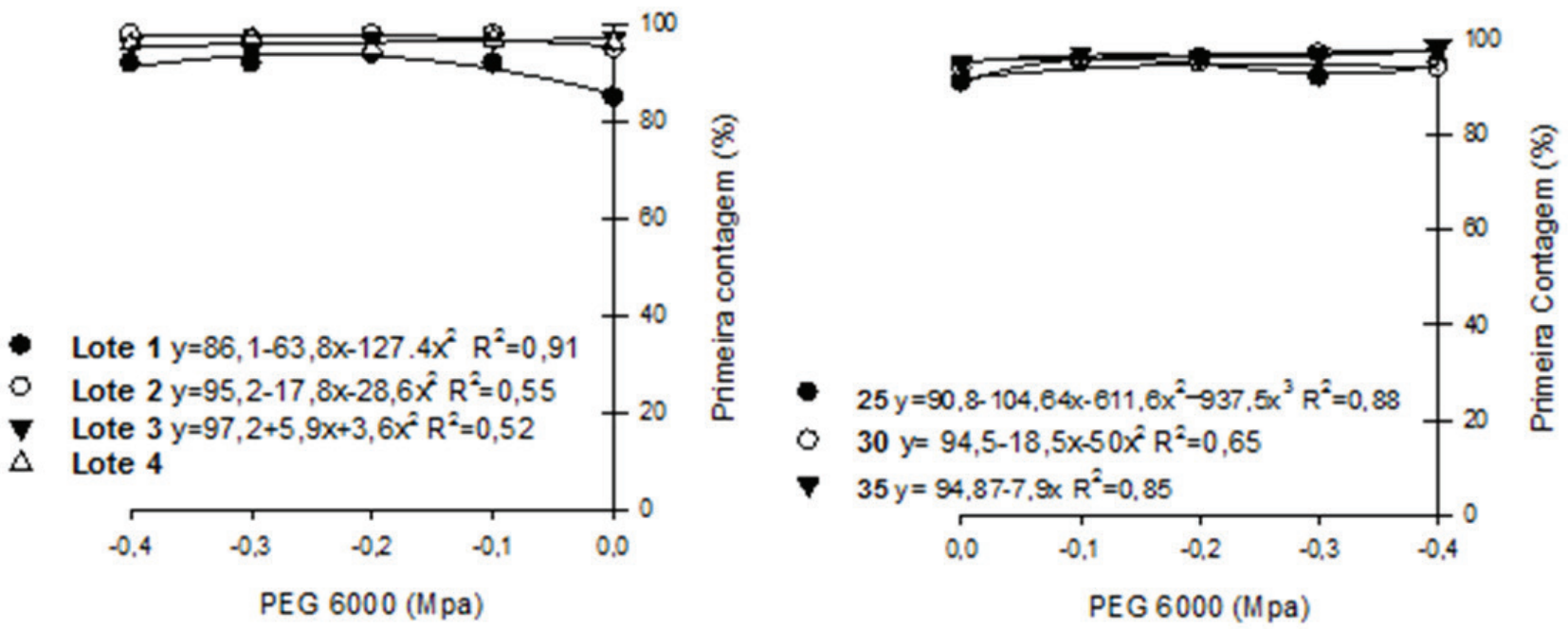

Figura 2 - Primeira contagem de germinação de sorgo sacarino com sementes osmocondicionadas (A) e submetidas a diferentes temperaturas (B). 
$\mathrm{A} \quad 25^{\circ} \mathrm{C}$

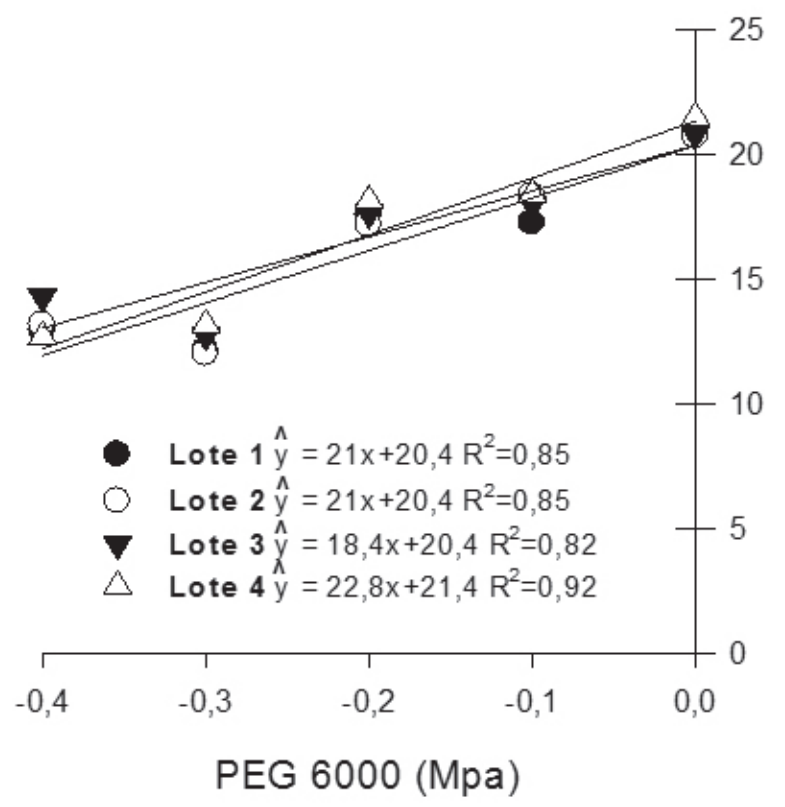

B

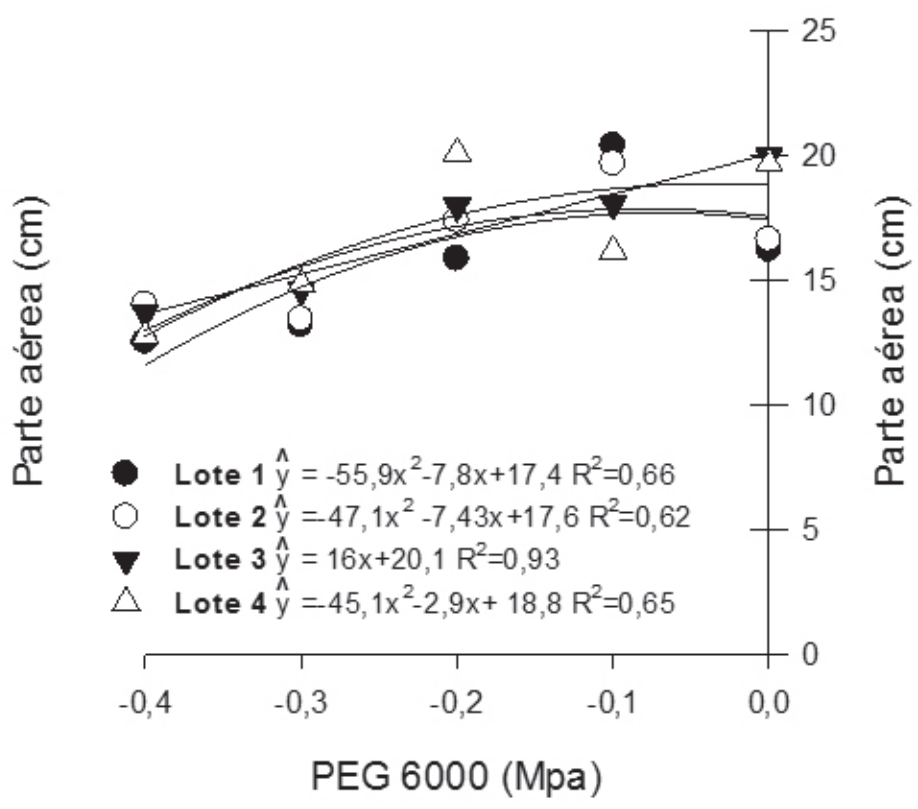

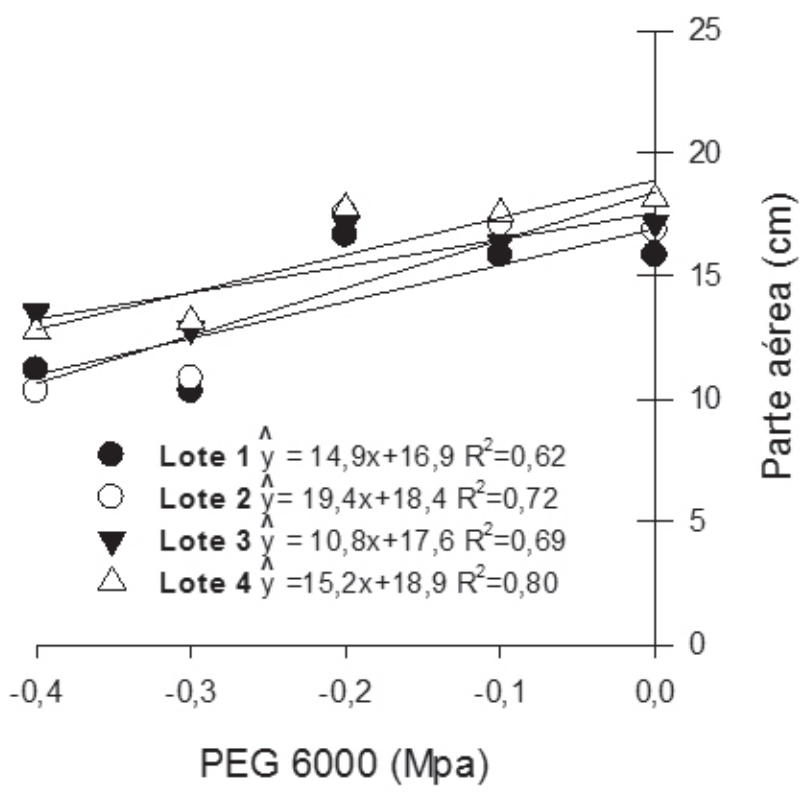

Figura 3- Efeitos do condicionamento osmótico de sementes de sorgo submetidas a diferentes temperaturas sobre a parte aérea das plântulas. 
valores não superaram os 15,00 centímetros (Figura 4). Esse incremento no comprimento radicular pode ser explicado por Taiz et al. (2017), em que, sob condições de estresse, a planta tende a diminuir a parte aérea, com uma maior quantidade de assimilados se alocando para o crescimento das raízes.

A

$25^{\circ} \mathrm{C}$

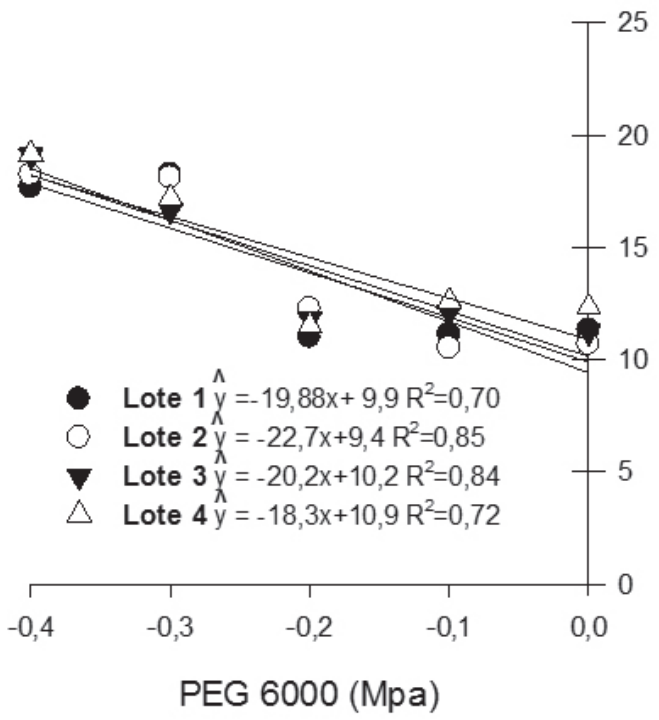

$\mathrm{C}$

$35^{\circ} \mathrm{C}$
A relação entre o crescimento radicular e o aéreo está representada na Figura 5. Observou-se que em todas as temperaturas avaliadas houve uma queda valores dessa relação, ou seja, o comprimento da parte aérea diminuiu enquanto o das raízes aumentaram. Percebeu-se também que com o aumento da tempe-
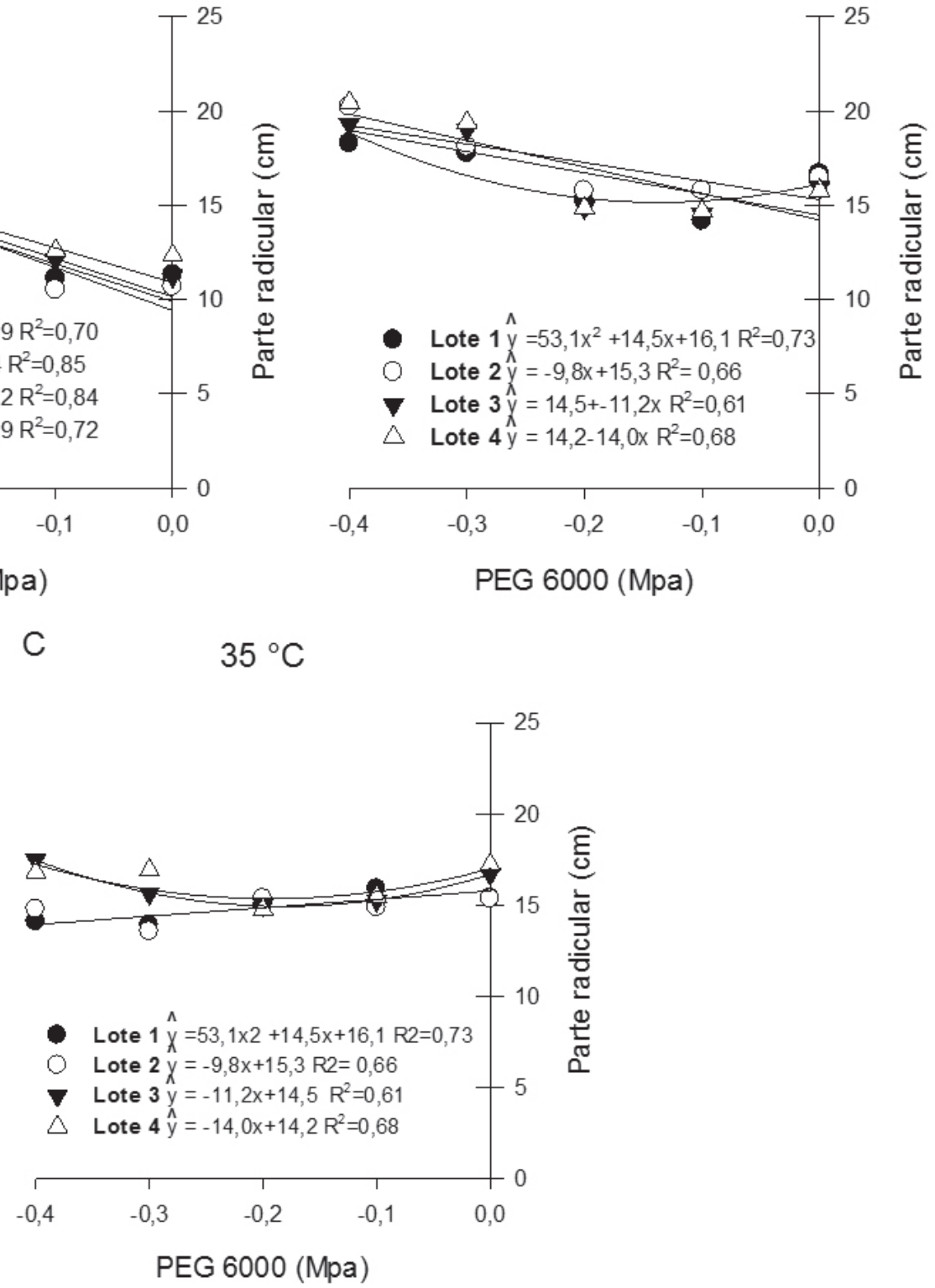

Figura 4- Efeitos do condicionamento osmótico de sementes de sorgo submetidas a diferentes temperaturas sobre a parte radicular das plântulas. 
ratura, o condicionamento osmótico não foi eficaz na promoção do crescimento, pois, em todas as concentrações de PEG 6000 avaliadas, o tratamento testemunha proporcionou os maiores índices. A temperatura de $35{ }^{\circ} \mathrm{C}$ apresentou simultaneamente os menores e os maiores valores para o crescimento radicular e o

A $25^{\circ} \mathrm{C}$

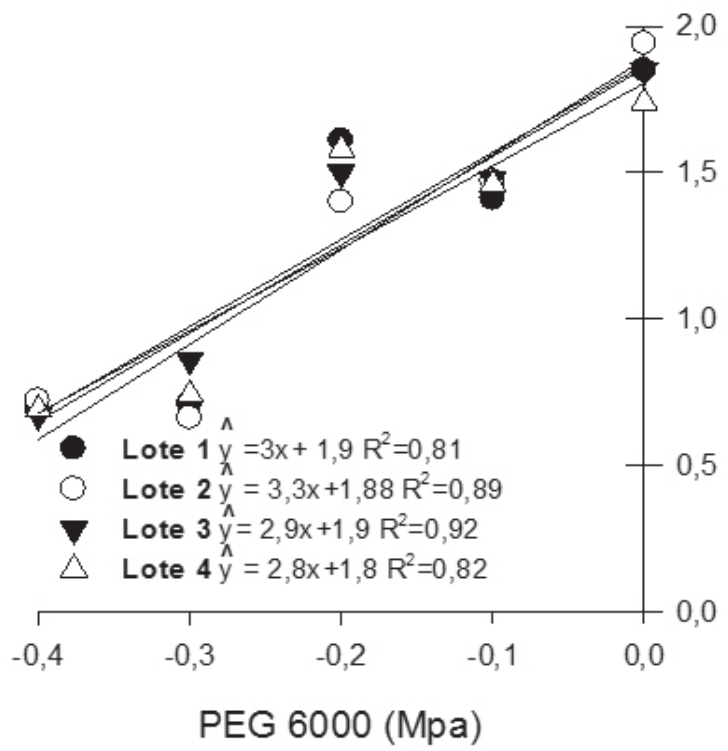

aéreo, respectivamente. Isso pode ter ocorrido devido ao estresse térmico, por ter causado danos ao metabolismo vegetal, influenciando na estabilidade proteica e nas reações enzimáticas, desestabilizando e desintegrando as estruturas secundárias de DNA e RNA (Taiz et al., 2017).
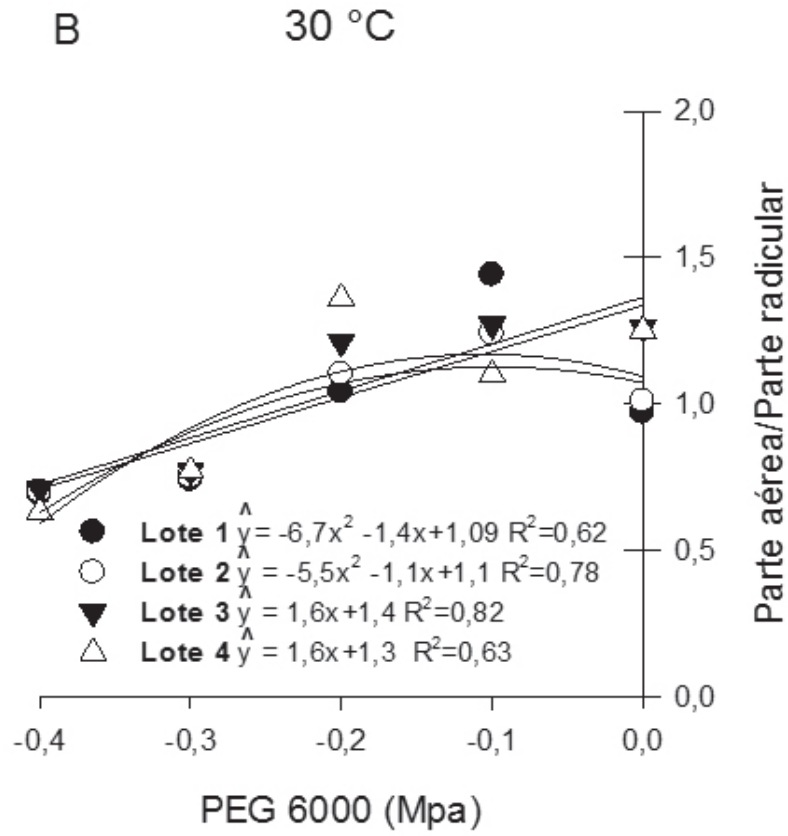

C $\quad 35^{\circ} \mathrm{C}$

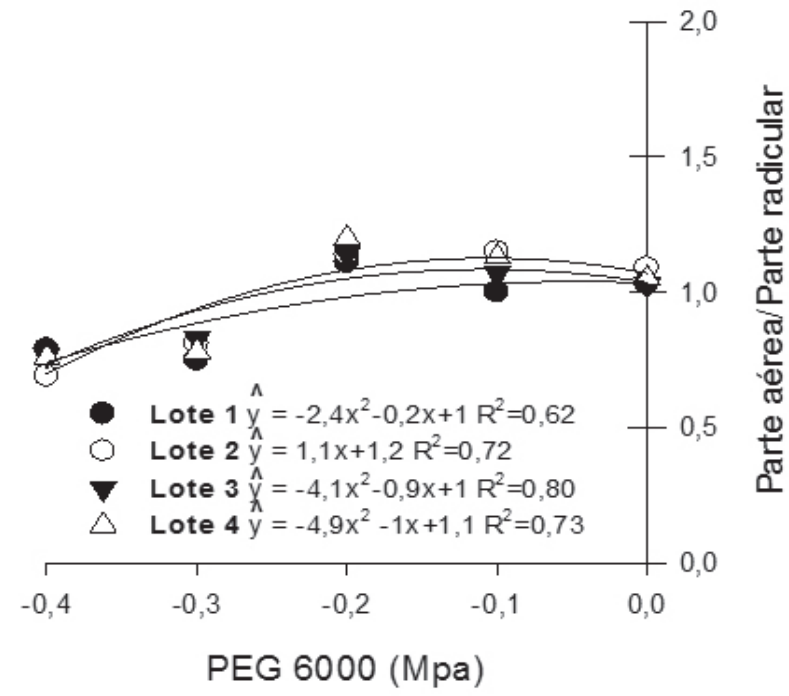

Figura 5 - Efeitos do condicionamento osmótico de sementes de sorgo submetidas a diferentes temperaturas sobre a relação parte aérea/parte radicular das plântulas. 
Para a variável massa seca na temperatura de $25^{\circ} \mathrm{C}$, os lotes testados apresentaram um declínio nos valores de massa seca até o condicionamento de $-0,2$ $\mathrm{MPa}$ e a partir desse valor houve uma recuperação para essa variável. A $30^{\circ} \mathrm{C}$, os lotes apresentaram um aumento crescente na massa seca quando submetidos ao condicionamento osmótico, com os lotes 3 e 4 apresentando uma redução nos valores dessa variável

A

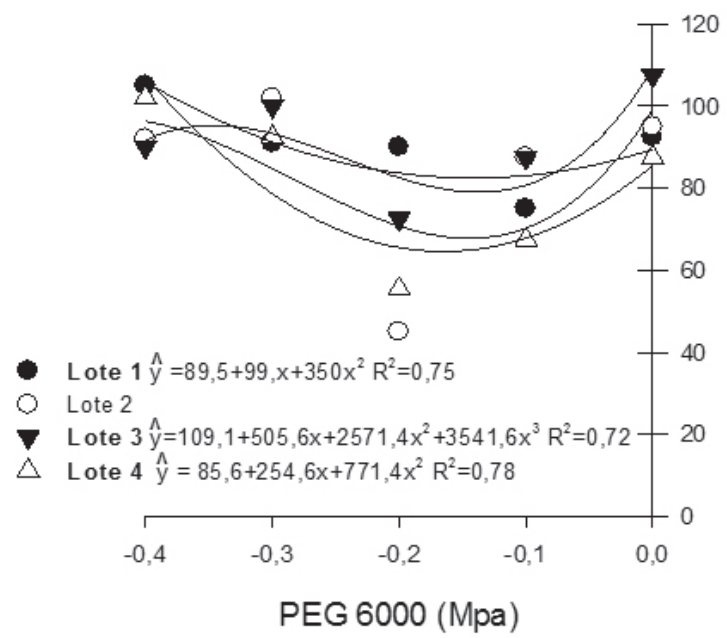

para maior concentração de PEG 6000 testada $(-0,4$ $\mathrm{MPa}$ ). Para a temperatura de $35^{\circ} \mathrm{C}$, o lote 3 apresentou uma oscilação nos valores médios da matéria seca no potencial de -0,4 MPa. Enquanto os lotes 1, 2 e 4 nessa mesma concentração apresentaram uma redução para essa variável, indicando que esses lotes quando submetido aos estresses osmótico e térmico podem se apresentam mais sensíveis (Figura 6).
B

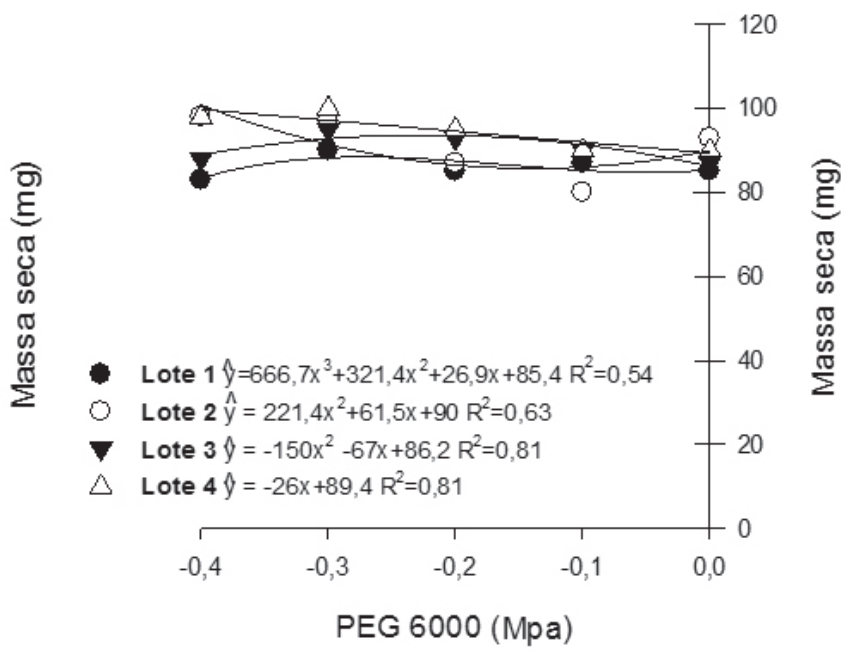

C $35^{\circ} \mathrm{C}$

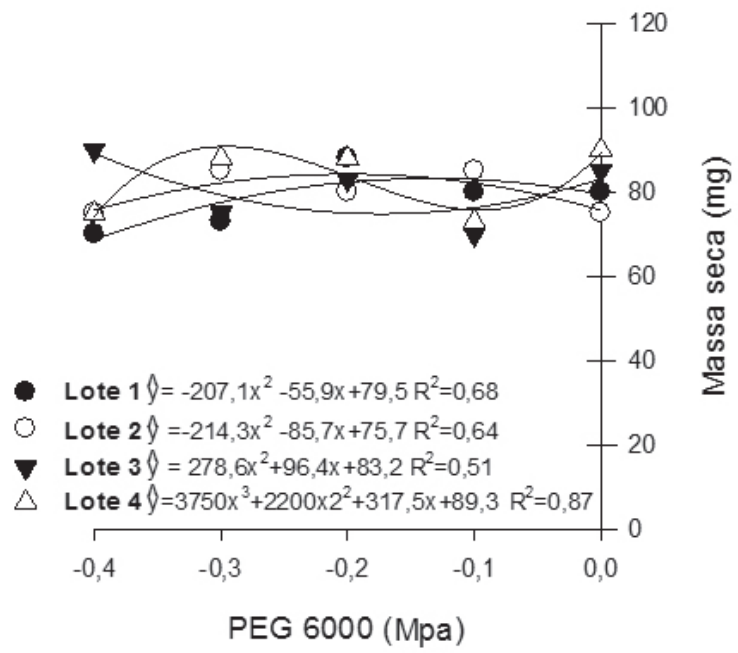

Figura 6 - Efeitos do condicionamento osmótico de sementes de sorgo submetidas a diferentes temperaturas sobre a massa seca de plântulas. 
Outros autores também relataram incrementos na fitomassa seca após o condicionamento das sementes, dentre eles, Oliveira e Gomes Filho (2011) em plântulas de sorgo condicionadas com $-0,86 \mathrm{MPa}$ de PEG 6000, sendo o acréscimo atribuído ao aumento do tamanho das raízes, levando a um aumento na biomassa produzida.

\section{Conclusão}

O condicionamento osmótico influenciou de forma positiva a germinação e a primeira contagem de germinação para as sementes de sorgo sacarino nas temperaturas testadas, permitindo uma separação dos lotes quanto ao seu desempenho fisiológico. ;

O condicionamento osmótico e o aumento da temperatura de germinação afetaram negativamente o crescimento das plântulas.

\section{Referências}

ALBUQUERQUE, C. J. B.; TARDIN, F. D.; PARRELLA, R. A. C.; GUimarães, A. S.; OliVeirA, R. M.; SILVA, K. M. J. Sorgo sacarino em diferentes arranjos de plantas e localidades de Minas Gerais, Brasil. Revista Brasileira de Milho e Sorgo, v. 11, n. 1, p. 69-85, 2012. DOI: 10.18512/1980-6477/rbms.v11n1p69-85.

BRASIL. Ministério da Agricultura, Pecuária e Abastecimento. Regras para análise de sementes. Brasília, DF, 2009. 395 p.

BEWLEY, J. D.; BLACK, M. Seeds: physiology of development and germination. 2. ed. New York: Plenum Press, 1994. 445 p.

CHRISTOVAM, M. C.; SILVA, T. L.; YAMAMOTO, C. J. T.; MOREIRA, A. L. L.; CUSTÓDIO, C. C.; PACHECO, A. C.; ABRANTES, F. L. Germinação e desenvolvimento inicial de plântulas de cultivares de Urochloa brizantha em condições de estresse hídrico. Informativo Abrates, v. 25, n. 1, p. 43-50, 2015.

CUNHA, S. P.; SEVERO FILHO, W. A. Avanços tecnológicos na obtenção de etanol a partir de sorgo sacarino (Sorghum bicolor (L.) Moench). Tecno-Lógica, v. 14, n. 2, p. 69-75, 2010.

FERREIRA, D. F. Sisvar: a computer statistical analysis system. Ciência e Agrotecnologia, v. 35, n. 6, p. 10391042, 2011. DOI: 10.1590/S1413-70542011000600001.

IBGE. Estatística da produção agrícola. Rio de Janeiro, 2017. $77 \mathrm{p}$.

KAPPES, C.; ANDRADE, J. A. C.; HAGA, K. I.; FERREIRA, J. P.; ARF, M. V. Germinação, vigor de sementes e crescimento de plântulas de milho sob condições de déficit hídrico. Scientia Agraria, v. 11, n. 2, p. 125-134, 2010. DOI: 10.5380/rsa.v11i2.16464.

LIMA, L. B.; MARCOS FILHO, J. Condicionamento fisiológico de sementes de pepino e germinação sob diferentes temperaturas. Revista Brasileira de Sementes, v. 32, n. 1, p. 138-147, 2010.

DOI: 10.1590/S0101-31222010000100016.

MEDEIROS, M. A.; TORRES, S. B.; NEGREIROS, M. Z.; MADALENA, J. A. S. Hidrocondicionamento e armazenamento de sementes de melão. Semina: Ciências Agrárias, v. 36, n. 1, p. 57-66, 2015.

DOI: $10.5433 / 1679-0359.2015 v 36 n 1 p 57$.

OLIVEIRA, A. B.; GOMES-FILHO, E. Estabelecimento de plântulas de sorgo oriundas de sementes osmocondicionadas de diferentes qualidades fisiológicas. Revista Brasileira de Ciências Agrárias, v. 6, n. 2, p. 223-229, 2011. DOI: 10.5039/agraria.v6i2a945.

OLIVEIRA, A. B.; ALENCAR, N. L. M.; GALLÃO, M. I.; GOMES FILHO, E. Avaliação citoquímica durante a germinação de sementes de sorgo envelhecidas artificialmente e osmocondicionadas, sob salinidade. Revista Ciência Agronômica, v. 42, n. 1, p. 223-231, 2011. DOI: $10.1590 / \mathrm{S} 1806-66902011000100028$. 
PELEGRINI, L. L.; BORCIONI, E.; NOGUEIRA, A. C.; KOEHLER, H. S.; QUOIRIN, M. G. G. Efeito do estresse hídrico simulado com $\mathrm{NaCl}$, manitol e PEG (6000) na germinação de sementes de Erythrina falcata Benth. Ciência Florestal, v. 23, n. 2, p. 511-519, 2013.

DOI: $10.5902 / 198050989295$.

PEREIRA FILHO, I. A.; PARRELLA, R. A. da C.; MOREIRA, J. A. A.; MAY, A.; SOUZA, V. F. de; CRUZ, J. C. Avaliação de cultivares de sorgo sacarino [Sorghum bicolor (L.) moench] em diferentes densidades de semeadura visando a características importantes na produção de etanol. Revista Brasileira de Milho e Sorgo, v. 12, n. 2, p. 118-127, 2013.

DOI: 10.18512/1980-6477/rbms.v12n2p118-127.

PEREIRA, M. R. R.; MARTINS, C. C.; MARTINS, D.; SILVA, R. J. N. Estresse hídrico induzido por soluções de PEG e de $\mathrm{NaCl}$ na germinação de sementes de nabiça e fedegoso. Biociência, v. 30, n. 3, p. 687-696, 2014.

REGO, S. S.; FERREIRA, M. M.; NOGUEIRA, A. C.; GROSSI, F.; SOUSA, R. K.; BRONDANI, G. E.; ARAÚJO, M. A.; SILVA, A. L. L. Estresse hídrico e salino na germinação de sementes de Anadenanthera colubrina (Veloso) Brenan. Journal of Biotechnology and Biodiversity, v. 2, n. 4, p. 37-42, 2011.

SBRUSSI, C. A. G.; ZUCARELI, C. Germinação de sementes de milho com diferentes níveis de vigor em resposta à diferentes temperaturas. Semina: Ciências Agrárias, v. 35, n. 1, p. 215-226, 2014.

DOI: $10.5433 / 1679-0359.2014 v 35 n 1 p 215$.

SIMONI, F.; COSTA, R. S.; FOGAÇA, C. A.; GEROLINETO, E. Sementes de Sorghum bicolor L. Gramineae, submetidas ao estresse hídrico simulado com PEG (6000). Revista de Biologia e Ciências da Terra, v. 11, n. 1, p. 188-192, 2011.

SILVA, M. L. M.; ALVES, E. U.; BRUNO, R. L. A.; SANTOS-MOURA, S. S.; SANTOS NETO, A. P. Germinação de sementes de Chorisia glaziovii o. kuntze submetidas ao estresse hídrico em diferentes temperaturas.

Ciência Florestal, v. 26, n. 3, p. 999-1007, 2016.

DOI: $10.5902 / 1980509824229$.

TAIZ, L.; ZEIGER, E.; MOLLER, I. M.; MURPHY, A. Fisiologia vegetal. 6. ed. Porto Alegre: Artmed, 2017.888 p.

VILLELA, F. A.; DONI FILHO, L.; SEQUEIRA, L. L. Tabela de potencial osmótico em função da concentração de polietilenoglicol 6.000 e da temperatura. Pesquisa Agropecuária Brasileira, v. 26, n. 12, p. 1957-1968, 1991.

ZUCARELI, C.; CAVARIANI, C.; OLIVIERA, E. A. P.; NAKAGAWA, J. Métodos e temperaturas de hidratação na qualidade fisiológica de sementes de milho. Revista Ciência Agronômica, v. 42, n. 3, p. 684-692, 2011. 